\title{
Systemic Risk Assessment: Aggregated and Disaggregated Analysis on Selected Indian Banks
}

\author{
Mohammed Arshad Khan $\left(\mathbb{D},{ }^{1}\right.$ Preeti Roy $\mathbb{D}^{2},{ }^{2}$ Saif Siddiqui $\mathbb{D D}^{2}$, and Abdullah A. Alakkas $\mathbb{I D}^{1}$ \\ ${ }^{1}$ Department of Accountancy, College of Administration and Financial Science, Saudi Electronic University, Riyadh 11673, \\ Saudi Arabia \\ ${ }^{2}$ Centre for Management Studies, Jamia Millia Islamia-Central University, New Delhi 110025, India
}

Correspondence should be addressed to Mohammed Arshad Khan; m.akhan@seu.edu.sa

Received 14 April 2021; Revised 17 June 2021; Accepted 1 July 2021; Published 9 July 2021

Academic Editor: Baogui Xin

Copyright (c) 2021 Mohammed Arshad Khan et al. This is an open access article distributed under the Creative Commons Attribution License, which permits unrestricted use, distribution, and reproduction in any medium, provided the original work is properly cited.

\begin{abstract}
Exposure of the banking system to the Global Financial Crisis attracted attention to the study of riskiness and spillover. This paper studies the pattern of systemic risk and size effect in the Indian banking sector. Based on market capitalization, three public sector banks and three from the private sector were taken. Data are taken from the year 2007 to 2020. The analysis is done through quantile-CoVaR (Conditional Value at Risk) and TENET (Tail-Event-Driven Network) measure. State variables like Indian market volatility and global risk measures negatively influence the Indian banks' returns. Liquidity risk is a crucial aspect of private banks. Public banks experience public confidence even in the distress period. Large banks like HDFC and SBI bank offer the highest degree of systemic risk contribution. The role of private banks in transmitting systemic risk has been intensifying since 2015. Small-sized banks like PNB and BOB have become significant receivers and transmitters of risk.
\end{abstract}

\section{Introduction}

As per the famous saying, "Never let a crisis go waste," the Global Financial Crisis (GFC) 2008 created an opportunity for revamping the financial system of the world's economies. It then became imperative to identify and address the pattern of dynamic linkages produced through common exposures and risk concentration across financial institutions, as corroborated by Adrian and Brunnermeier [1].

Consequently, the Financial Stability Board was established in the G20 summit by the International Monetary Fund and Bank of International Settlements in 2010. Borio [2] emphasized that the former's objective was to contain the system-wide risks and concurrent downswings posed by key financial institutions in terms of disruptions and losses to the real economy. The goal was to achieve financial stability.

Banks are the primary institution to fuse financial liquidity for the proper functioning of the financial system and ensure stability, as proposed by Mishra, Mohan, and Sanjay [3]. However, they are equally considered a principal channel of stress transmission through their complex web of lendingborrowing relationships [4]. The risk spreads to other financial institutions in the form of liquidity crunches; those are exposed to the same securitized asset or repo. According to Acharya and Steffen [5], the systemic risk arises if there is a systemic liquidity crisis such that the interbank funding dries up. Its source of generation is also complex due to the involvement of both country-level and institution-specific factors. Chakrabarty [6] says that in the Indian domain, financial sector assets contribute $150 \%$ of its GDP.

As per India Brand Equity Foundation [7], the share of commercial banks in its financial sector is $64 \%$ of total assets, the majority of which is under government ownership, Eichengreen and Gupta [8]; i.e., public banks own $72 \%$ of commercial banks' assets as per Indian Banking Industry report of India Brand Equity Foundation, [9]. India set up the Financial Stability and Development Council (FSDC) in 2010. It addresses the interconnectedness of the Indian financial system through proper systemic risk assessment measures. 
Its banking sector is also crippled in the unique problem of "Twin Balance Sheet Syndrome" since 2015 and reflected unique characteristics of expansionary demand growth with overleveraged companies facing debt-servicing issues as per the Indian Economic Survey [10]. The outcome was the double digits nonperforming assets, miring of the commercial banks with Nonbanking Financial Companies (NBFCs), and Housing Finance Companies (HFCs), thereby exposing the commercial banks to a greater degree of interconnectedness as per the Financial Stability Report of RBI [11]. Subramanian and Felman [12] suggested that the earlier syndromes transformed into the "Four Balance Sheet Challenge", entangling the four sectors banking, infrastructure, shadow banking, and real estate companies.

Four approaches measured the estimation of systemic risk. The primary one was the stress test proved inadequate by Brunnermeier [13] and Gorton and Metrick [14]. This was followed by the macrostress testing approach by Greenlaw et al. [15], Burrows et al. [16], and Erdem et al. [17]. Then, tail dependence measures, systemic risk index, and expected shortfall measures were developed by Brownlees and Engle [18], Adrian and Brunnermeier [1], and Acharya et al. [19]. These approaches were based on local interdependence, i.e., between the financial institution and the whole system. At the same time, a relatively new approach was through network graphs which were followed by Demirer et al. [20], Wang et al. [21], and Härdle et al. [22]. These graphs are powerful enough to represent the complexity within the financial system, which could be revealed through nodes and edges.

The paper is an attempt to understand the pattern of the interconnectedness of Indian public and private banks. It contributes to the issue of systemic risk of Indian banks [23] of the various topics like the performance of banks [24], nonperforming assets [25], credit risk [26], etc. This is further assessed through the sensitivity of each bank to the macroeconomic variables and each other, as Adrian and Brunnermeier [1] suggested that the interaction of banks cannot be studied in isolation to its exogenous factors. It also overcomes the limitation of the earlier measure of systemic risk, which assumed variables to be normally distributed.

It adopts tail-based systemic risk measures like CoVaR (Conditional Value at Risk) and TENET (Tail-Event-Driven Network Risk). TENET methodology is better than the one adopted by Billio et al. [27], based on Granger-causality connectedness as the events of the latter capture at means of the returns distribution and give fewer weights to the information at the extreme ends.

This allows us to bring out a holistic picture of systemic risk at both disaggregated and aggregated levels. The timevarying aspect is also added. Finally, it assesses the contribution risk in the form of a significant systemic risk receiver (SRR) and systemic risk emitters (SRE) through the directional spillover networks. The paper extends the study by Verma et al. [23] by investigating whether the NBFC crisis initiated in September 2018 triggered tail interconnectedness or showed resilience among the topmost private and public banks in terms of market capitalization. NBFC crisis has enhanced the risk exposure of Indian commercial banks in subscription of commercial papers, extending the line of credit, and repurchasing the existing loans [28]. The liquidity crunch in NBFCs will be followed by contagion risk to the commercial banking sector. Along with the NBFC crisis, the COVID-19 effect was examined. The six topmost banks are selected as these banks are considered to be Systemically Important Banks (SIBs), and any solvency shocks create an alarming signal for the government and policymakers to offer a timely resolution.

It proposes seeking the answers to the following questions. Does heterogeneity in banks persist in the Indian banking system due to its size effect? Are the large banks so large enough to cause risk spillover? Are small banks vital sufficient to deepen a crisis, as proposed by Jiang and Zhang [29]?

The paper is structured as follows: In Section 2, the theoretical background is built upon the systemic risk and is titled "Literature Review." Section 3 explains the "Methodology and Data" used for the study, followed by "Empirical Analysis" in Section 4. The last section presents the "Conclusions" of the study.

\section{Literature Review}

Most of the studies were based on developing a new measure for systemic risk, which could converge both institutional and country-specific factors to provide a broader outlook.

Kleinow and Nell [4] attempted to analyze the factors driving the systemic risk among the set of European banks. The study applied both the contribution and sensitivity approach in terms of CoVaR and MES (Marginal Expected Shortfall) measures to capture the systemic risk. The new index called the systemic risk index was developed. The highest systemic exposure was found during the crisis periods. Some banks became relatively "too big" to systemically influence others. The study by Le [30], by applying the same measure to the banking sector of 6 ASEAN economies, has found that systemic risk is linked to size, quality of the loan, and market to book value. Banks experienced strong regional connectedness rather than the one experienced during the time of GFC. Elyasiani and Jia [31] investigated whether the size matters to trigger systemic risk via the systemic risk index measure. It was found that downsizing measures would not be better as the small banks could trigger the crisis. The focus should be given to the net effect of the strength and weakness of large banks in the US.

While the study was done by Acharya and Steffen [5] on European banks using the MES risk measure from 2007 to 2011, it was found that sovereign debt holdings significantly could explain the systematic risk. The study emphasized that the undercapitalization of banks could alter the findings of the study. Karimalis and Nomikos [32] investigated each European bank's contribution to systemic risk via copula-based CoVaR and Conditional Expected Shortfall from 2007 to 2012. French and Spanish banks have the highest systemic risk. Common market factors like industrial production, GDP, unemployment, and stock market were important for propagating systemic risk. Yun and Moon [33] explored the systemic risk phenomena in 10 
Korean banks from 2002 to 2013. The two estimates of systemic risk, i.e., the CoVaR and MES, were estimated via DCC models. The relation between systemic risk and bankspecific characteristics was studied. VaR of individual banks influenced the systemic risk. Roengpitya and Rungcharoenkitkul [34] found the systemic risk in six central Thai banks from 1996 to 2009 through CoVaR via quantile regression. It was found that Thai banks stimulated the risk factor of the banking industry during the Asian Crisis. The banks with greater size caused the systemic risk.

Hashem and Abdeljawad [35], through CoVaR and MES, have measured the vulnerability between Bangladeshi Islamic and Conventional Banks. It was found that the conventional banking system was riskier than the Islamic banking system. Huang, De Haan, and Scholtens [36] attempted to capture the systemic risk in 16 Chinese banks from 2007 to 2014 through CoVaR, MES, Systemic Impact Index, and Vulnerability Index measures. It was revealed that the rankings by different methods tend to diverge but were correlated. The systemic risk narrowed after the GFC but again galloped after 2014 .

Jiang and Zhang [29] also attempted to investigate the systemic risk in 16 Chinese banks from 2011 to 2018 via an indicator approach and a market-based approach. It was found that the indicator approach complements the other one. Dynamic CoVaR was further modeled to include state variables. It was found that small banks became vital for the system in one phase, while for the other phase, the large banks were identified as systemically important. Acharya et al. [19] measure the institutional contribution of US institutions to systemic risk via MES and SES (Systemic Expected Shortfall) measures. The models could predict such contributions. Further, short-term leverages like repos, commercial papers, and deposits were found to have a pronounced effect in causing the systemic risk during the crisis.

Some studies highlighted the interconnections between the banks and financial institutions which may arise due to systemic risk. Härdle et al. [22] introduced TENET and the Single Index Model to study the systemic risk and then the interconnectedness among the financial institutions. It was evidenced that depositories were the ones who were the systemic risk-takers and emitters, while the insurer's role was minimal during GFC. Verma et al. [23] identified the interlinkages between the government-owned and private Indian banks with a sample of 18 and 13 banks, respectively, from 2007 to 2017. The results from the VaR, CoVaR, and Single Index Model in quantile regression revealed systemic risk during the crisis periods. Huang et al. [37] investigated the systemic risk contribution of 39 financial institutions in China from 2011 to 2015. CoVaR was estimated using the DCC-GARCH model. It was found that firms with greater node strength had more significant contributions to systemic risk. Demirer et al. [20] have estimated the global bank interconnections with the sample of 150 banks from the USA, Australia, Japan, Canada, China, Singapore, Malaysia, Korea, and India from 2004 to 2014. It was found that the connectedness has extended over bad times. The small banks could transmit shocks to the whole system during bad times, causing systemic inferences.
Clemente et al. [38] have investigated the systemic risk in the European banking system from 2003 to 2017 using market data. The evidence of systemic risk via clustering coefficients indicating the strength of interconnectedness was found during the crisis. Chabot and Bertrand [39] investigated the financial connectedness of 262 financial institutions from 2000 to 2015 through network analysis. The results revealed that the banks were connected to those with a high reputation, i.e., those which can be rescued by the government and enjoy implicit guarantees.

Some studies have pointed out that the bank's role in contributing to systemic risk is the maximum across all other financial institutions. Oscar et al. [40] investigated the contribution of banks, insurance, and other financial sectors to systemic risk in Europe and the USA from 2004 to 2012. $\mathrm{CoVaR}$ risk was used to measure the risk. The quantile regression estimates highlighted that other financial firms and banks were the systemically riskiest in Europe during the distress periods. At the same time, insurance was systemically riskiest in the USA. Girardi and Ergün [41] investigated the systemic risk contribution of 74 US financial institutions from 2000 to 2008. An investigation was done on four groups: banks, insurance, brokerage, and other financial firms. Industrywise, time-varying $\mathrm{CoVaR}$ was obtained via the DCC-GARCH model. Castro and Ferrari [42] made an investigation from a sample of 26 European banks from 1999 to 2012. It was found that only a few banks could be considered systemically crucial following the CoVaR approach. Diebold and Yilmaz [43] have investigated connectedness in US financial institutions from 1999 to 2010 . The sample includes 13 institutions of categories like commercial banks, investment banks, insurance companies, and mortgage companies.

Billio et al. [27] investigated the interlinkages between the four categories of financial institutions, i.e., banks, brokers, hedge funds, and insurers. The interlinkages were found to be solid and complex due to asymmetry and nonlinearities estimated by Granger causality. However, banks were identified as the financial institutions responsible for transmitting shocks to others. Wang et al. [44] investigated the multilayer interconnectedness across the Chinese SIBs and an insurance group called SIFIs (Systemically Important Financial Institutions) from 2008 to 2018. The Granger-causality test was extended for capturing mean, volatility, and extreme risk nuances. The results revealed that such a model provided an early warning signal before the eve of the European and Chinese stock market crash of 20152016. Banks exhibited a greater degree of overlap. Wang et al. [45] extended the study to include 30 Chinese financial institutions from three groups, i.e., banks, securities, and insurance, from 2011 to 2018 . A similar multilayer technique was adopted at variance decomposition setting. The spike in spillover was found before the Chinese stock market crisis and weak information transmission between volatility and extreme risk layers.

Studies like [46] showed how systemic risk occurring in financial markets can percolate to the real economy and how the gap between real activity and financial activity is blurred. The study was based on finding the relation between the financial market-wide systemic risk and the macroeconomic 
downturn in the USA and Europe from 1946 to 2011 and from 1994 to 2011. It was found that Industrial Production growth, Chicago Fed National Activity Index, equity volatility, and Fed Fund rate were all severely influenced by the rise in the systemic risk. Bianconi et al. [47] showed how market sentiment could aggravate the systemic risk in financial markets. The two measures, i.e., the VIX and consumer pessimism, were adopted to analyze 14 US financial institutions from 1992 to 2006.

From the existing literature review, it is clear that the studies on assessing the systemic risk in the Indian context are limited either to the conventional measures or to the time dimension. Since the pattern of riskiness is a continuously evolving pattern, it is thus imperative to study the systemic risk in Indian banks in recent times when it is feeling the stress from the NBFC sector. Further, the possible channels of systemic risks in Indian banks were needed to be demystified. The study also compares both the conventional and advancing measure of systemic risk, which was yet to be studied.

\section{Methodology and Data}

3.1. Methodology. To measure the interbank risk spillover emerging from the extreme events in a single financial institution, Adrian and Brunnermeier [1] proposed the Conditional Value at Risk (CoVaR) model through a bivariate setting of linear quantile regression. This model was better than VaR because it effectively measures an institution's contribution to system-wide risk [29] while the latter only measured the risk prevalent in a single institution on a standalone basis.

Accordingly, the institutional VaR is defined as

$$
P\left(X_{t}^{i} \leq \operatorname{VaR}_{t, \tau}^{i}\right)=\tau \%,
$$

where $\tau$ is the specified quantile and $X_{t}^{i}$ is the returns of bank $i$ by $t$ th time.

The risk spillover measured through CoVaR takes accounts for the state variables to capture the tail risk connectedness. The CoVaR of institution $k$ at time $t$ is denoted by

$$
P\left(X_{t}^{k} \leq \mathrm{CoVaR}_{t, \tau}^{k \mid i} \mid I_{t}^{i}\right)=\tau \%,
$$

where $I_{t}^{i}$ is the conditional information on the event of $X_{t}^{i}=$ $\mathrm{VaR}_{t, \tau}^{i}$, and $S_{t-1}$ as a vector of state variables. Accordingly,

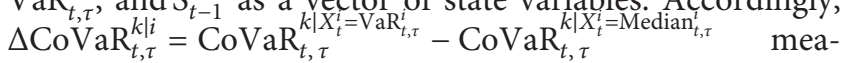
sures the incremental contribution of the financial institution to system-wide risk when $i$ is shifting from a normal situation to a distress situation.

3.2. Tail-Event-Driven Network (TENET). Adrian and Brunnermeier [1] measured the systemic risk between two institutions with quantile regression independently. This setup ignored the high dimensionality, which causes the interactions between all the financial institutions in the setup. This problem was subdued by Härdle et al. [22]. The TENET procedure consists of three steps.
First, a linear quantile regression model is estimated as

$$
\begin{aligned}
X_{t}^{i} & =C_{i}+\theta_{i} S_{t-1}+\varepsilon_{t}^{i}, \\
X_{t}^{k} & =C_{k \mid t}+\theta_{k \mid i} S_{t-1}+\Phi_{k \mid i} X_{t}^{i}+\varepsilon_{t}^{k \mid i},
\end{aligned}
$$

where $X_{t}^{i}$ and $X_{t}^{k}$ are the returns of bank $i$ and $k$ at time $t . \Phi_{k \mid i}$ is the responsiveness of bank $k$ to changes in returns of bank $i$ corresponding to the tail event. Second, CoVaR is estimated by placing the estimated $\mathrm{VaR}_{t, \tau}^{i}$ in equation (5) to equation (6).

$$
\begin{aligned}
\operatorname{VaR}_{t, \tau}^{\prime i} & =C_{i}^{\prime}+\theta_{i}^{\prime} S_{t-1}, \\
\mathrm{CoVaR}_{t, \tau}^{\prime k \mid i} & =C_{k \mid t}^{\prime}+\theta_{k \mid i}^{\prime} S_{t-1}+\Phi_{k \mid i}{ }^{\prime} \mathrm{VaR}_{t, \tau}^{\prime i},
\end{aligned}
$$

where $\Phi_{k \mid}{ }^{\prime}$ represents the extent of interconnectedness. Here, $k$ is the system-wide returns and $i$ is the individual returns of the institution. This step was obtained through a single index model via quantile regression to obtain the contribution $\mathrm{CoVaR}$ of the individual bank with the relevant banks based on tail events and interactions.

Furthermore, the directional spillover can be estimated as follows:

$$
\begin{aligned}
\Phi_{k, t} & =f \cdot\left(\Phi_{k \mid i}^{T} \cdot M_{k, t}\right)+\varepsilon_{k, t}, \\
\operatorname{CoVaR}_{t, \tau}^{\prime k \mid i} & =f^{\prime} \cdot\left(\Phi_{k \mid M_{k}}^{\prime T} \cdot M_{k, t}^{\prime}\right), \\
D_{k, M_{k, t}}^{\prime} & =\delta f^{\prime}\left(\Phi_{k \mid M_{k}}^{\prime T} \cdot M_{k, t}^{\prime}\right) \Phi_{k \mid M_{k}}^{\prime},
\end{aligned}
$$

where $M_{k, t}=\left\{x_{k t}, S_{k, t-1}\right\}$ represents the including $x_{k t}=$ $\left\{x_{1 t}, x_{2 t}, \ldots, x_{n t}\right\}$ which are independent variables of all the banks taken in the sample except for $k$ th bank. $\Phi_{k \mid M_{k}}=$ $\left\{\Phi_{k \mid-k}, \Phi_{k \mid s}\right\}$ are the static parameters.

For dynamic estimations, the rolling window size is taken as $n=48$ for a year's weekly data. $D_{k, M_{k, t}^{\prime}}^{\prime}$ represents the marginal covariate effects through gradient descent measure. $\mathrm{MC}_{k, s}$ stands for market capitalization of the kth entity. This shows the network spillovers. Networks are based on partial derivatives of other banks; i.e., $\Phi_{k \mid-k} \cdot \tau$ th quantile is considered $1 \%$ and $5 \%$.

In the final step, the Systemically Important Banks are identified on SRR (Systemic Risk Receivers) and SRE (Systemic Risk Emitters) estimates as follows:

$$
\begin{aligned}
& \operatorname{SRR}_{k, s}=\mathrm{MC}_{k, s} \cdot\left(\sum_{i \in Z_{s}^{\text {in }}}\left(\left|D_{k, i}^{\prime s}\right| \cdot \mathrm{MC}_{k, s}\right)\right), \\
& \operatorname{SRE}_{k, s}=\mathrm{MC}_{k, s}\left(\sum_{i \in Z_{s}^{\text {out }}}\left(\left|D_{i, k}^{\prime s}\right| \cdot \mathrm{MC}_{k, s}\right)\right) .
\end{aligned}
$$

3.3. Data. For the study, weekly data from 1 st January 2007 to 31st March 2020 is taken consisting of a sample of 3 public and 3 public sector banks in India. The list of banks considered for the study is presented in Table 1. 
TABLE 1: List of banks and macrostate variables.

\begin{tabular}{lcc}
\hline Public banks & Public banks market capitalization in Rs & Symbols \\
\hline State Bank of India & 2727.73 billion & SBI \\
Punjab National Bank & 23.478 billion & PNB \\
Bank of Baroda & 38.452 billion & BOB \\
\hline Private banks & Market capitalization in Rs & HDFC \\
HDFC Bank & 5605.4 billion & ICICI \\
ICICI Bank & 2128.7 billion & AXIS \\
AXIS Bank & 1643.59 billion & Description \\
Macrostate variables & VIX is an implied volatility (IV) measure of investor fear gauge derived from S\&P 500 options & VIX \\
Global risk & Indian stock market risk derived from implied volatility measure of nifty 50 options price & IVIX \\
Market risk & Realized volatility measure of USD/INR exchange rate calculated * & EV \\
Exchange rate volatility & Weighted average call rate - RBI repo rate captures the liquidity stress among banks & LIS \\
Liquidity spread & &
\end{tabular}

${ }^{*} \mathrm{VOL}_{t}=\sum_{t=0}^{n} \mathrm{ER}_{t}^{2}$; here, ER is the change in the exchange rate and $t$ is a window of 10 days.

Ideally, the Twin Balance Sheet Syndrome was vigilant in 2015 in the Indian banking system; however, its history was related to the 2007-2008 crisis period as per the Indian Economic Survey [10]. Hence, it motivated us to trace the pattern of connectedness among Indian banks from the 2007 crisis. Apart from that, the period could also capture the effect of the IL\&FS crisis during 2018-2019 and reflect the initial signs of the Coronavirus pandemic on the Indian banking system.

The bank's selection is based on market capitalization values, as quoted from the Business Today report. The data on the macrostate variable is taken from the Reserve Bank of India. Four state variables were included for the study, i.e., the global risk, exchange rate volatility, market volatility, and funding risk as identified by a systemic risk survey conducted by the Reserve Bank of India [48]. Further, Shin [49] proposes that excessive asset growth contributes to systemic risk by fostering interconnectedness in financial institutions.

\subsection{Empirical Analysis}

3.4.1. Preliminary Analysis. From the descriptive summary in Table 2, inferences on the essential characteristics of the set of public and private banks can be drawn. All three public sector banks offer a weekly negative return. Of the three public banks, the SBI offers the highest weekly returns on average, followed by BOB. SBI returns tend to exhibit the lowest volatility, and PNB shows the highest volatility. While the private sector banks offer positive weekly returns on average. HDFC bank offers the highest returns and highest volatility. The lowest return is exhibited by ICICI bank.

From the skewness estimates, it can be observed that the weekly returns of all the public sector banks are positively skewed, signaling that a lot of observations lie on the right end of the returns distribution with a fatter tail. In comparison, private sector banks like HDFC displayed a fatter right end tail. But the other two banks exhibited negative skewness with a lot of observations on the left end. The kurtosis measures depict that the two public sector banks' returns distribution is platykurtic. In comparison, PNB describes leptokurtic distribution with a lot of extreme events. The two private sector banks like HDFC and ICICI show the leptokurtic distribution. At the same time, AXIS shows the platykurtic distribution.

From these preliminary findings, it can be concluded that the bank's returns series have asymmetry and contain extreme events which cannot be captured by standard regression measure.

Quantile regression estimates from Table 3 and 4 depict the relationship between the set of macrovariables and set of banks at normal (50\% quantile) and stress periods (1\% and $5 \%$ quantile). Table 3 reveals that, during the stress period, all the private sector banks taken together are negatively influenced by the change in VIX and change in IVIX as macrofactors. During a normal period, liquidity spread exhibits positive relationships with all public banks. Exchange rate volatility does not influence any of the banks.

The returns of ICICI and AXIS banks positively influence all the public banks during all periods. HDFC banks affect the returns of public banks only during the normal period. During the normal period, the change in IVIX negatively influences only the SBI returns. Liquidity spread also positively influences PNB and AXIS banks only during a normal period. HDFC bank exhibits a negative influence on PNB at $50 \%$ quantile. Both ICICI and AXIS banks are directly related to the $\mathrm{SBI}, \mathrm{PNB}$, and $\mathrm{BOB}$ at stress and a normal period.

Table 4 reveals that all the private sector banks taken together exhibit aversion to any of the macrofactors during the stress period. They only get impacted by SBI returns during the stress period. During a normal period, changes in VIX produce a negative impact on all private banks. All the public banks potentially influence the returns of all private banks during a normal period. The VIX changes negatively impact the ICICI and AXIS banks during the stress period and on the normal period. But the IVIX negatively influences the ICICI and AXIS bank only during the stress period.

The liquidity spread exhibits negative relation with ICICI and AXIS banks during the stress period only. Exchange rate volatility negatively influences the AXIS bank's returns at both $1 \%$ and $5 \%$ quantiles. SBI returns exhibit a positive influence on the returns of all banks during normal periods 
TABLe 2: Descriptive summary.

\begin{tabular}{|c|c|c|c|c|c|c|}
\hline & \multicolumn{3}{|c|}{ Public banks } & \multicolumn{3}{|c|}{ Private banks } \\
\hline & SBI & PNB & BOB & HDFC & ICICI & AXIS \\
\hline Median & 0.0015 & 0.0011 & 0.0011 & 0.0037 & 0.0012 & 0.0014 \\
\hline Mean & -0.0001 & -0.0018 & -0.0006 & 0.0029 & 0.0009 & 0.0014 \\
\hline Maximum & 0.2766 & 0.4174 & 0.2568 & 0.7145 & 0.2415 & 0.2554 \\
\hline Minimum & -0.1978 & -0.2514 & -0.217 & -0.6874 & -0.3271 & -0.2841 \\
\hline Variance & 0.0028 & 0.0036 & 0.0033 & 0.0072 & 0.0035 & 0.0033 \\
\hline Std dev & 0.0524 & 0.0604 & 0.0575 & 0.0851 & 0.0588 & 0.0572 \\
\hline Skewness & 0.3061 & 0.403 & 0.0995 & 0.3424 & -0.3954 & -0.3994 \\
\hline Kurtosis & 2.318 & 4.6099 & 1.9353 & 50.1626 & 3.6042 & 2.5428 \\
\hline Observations & 652 & 652 & 652 & 652 & 652 & 652 \\
\hline
\end{tabular}

and ICICI and AXIS banks during stress periods. The magnitude of the effect of SBI is the most during the stress period in both these banks. PNB and BOB influence the ICICI bank and AXIS bank, respectively, during the stress period.

Several inferences can be drawn from the static quantile regression estimates:

(i) The general perception of investor's fear reflected through "volatility indices" negatively influences the bank's returns, especially during the stress period. The public and private banks tend to be substantially affected by Indian volatility index measures than the US measure reflected through the absolute value of coefficients. The liquidity spread used as a measure for "liquidity risk" exhibits a negative relation with the two private banks, i.e., ICICI and AXIS banks, during the stress period. In comparison, the public banks show a positive relationship with liquidity spread during a normal period. This signals that a rise in the liquidity spread during the stress period does not induce panic behavior of investors leading to the sale of stocks of public banks. But this trend is reversed in the case of private banks except for HDFC, which still displays resilience to liquidity risk

(ii) The public banks display resilience to exchange rate volatility, but AXIS bank does not. As a result, the returns of only AXIS bank tumbles with the sudden fluctuations in exchange rate experienced during the stress period

(iii) Of the private sector banks, HDFC shows resilience to all the macroeconomic factors

(iv) The public banks, especially SBI, exert a greater positive influence on private banks during stress and normal periods while two private banks, the ICICI and AXIS banks, substantially influence the public banks

3.5. Disaggregated Analysis. This section provides an institutional-level analysis of systemic risk. The contribution of each bank was estimated through $\mathrm{VaR}$ and CoVaR estimates.

Table 5 presents the summary of time-varying VaR estimates in which there is the individual risk contribution of each bank at both $5 \%$ and $50 \%$ quantiles. PNB has the highest VaR of $8.96 \%$ among all the banks. HDFC has the highest VaR of $7.77 \%$ among the private banks. ICICI has the lowest VaR of $6.68 \%$ during the period of stress. This would mean that investors holding PNB stock in the portfolio have a $5 \%$ chance of losing at least $8.96 \%$ of the portfolio and a $50 \%$ chance of losing $0.17 \%$ of the portfolio. Among all the banks, the maximum loss on investment in ICICI stocks is limited to $6.68 \%$ with a $95 \%$ confidence level.

A high VaR does not mean that the bank will have an increased contribution to the systemic risk during the distress period. For assessing the systemic risk contribution produced by each bank, CoVaR is estimated.

Table 6 presents the summary of the time-varying CoVaR model. PNB has the highest CoVaR of $6.4 \%$ and $6.34 \%$, respectively, at $1 \%$ and $5 \%$ quantiles among the public banks. This would mean that in the distress period at $\mathrm{PNB}$, the bank contributes to the system-wide average loss of $6.34 \%$ to $6.4 \%$. Among all banks, HDFC bank has the highest CoVaR of $7.05 \%$ and $7.59 \%$ at $1 \%$ and $5 \%$ quantiles, respectively, with the highest volatility in $\mathrm{CoVaR}$ of $6.13 \%$ to $8.81 \%$. This signals that if the HDFC bank faces distress, it contributes an average loss of $7.05 \%$ to $7.59 \%$ to other banks. The least contribution to systemic risk is offered by ICICI bank, i.e., $5.2 \%$ to $5.36 \%$. On the other hand, the average contribution to systemic risk by private banks is observed to be higher.

Figure 1 presents the time-varying estimates of returns of specific banks, VaR (at 50\%) and CoVaR (at 5\%) represented in black, green, and red colors. From the figure, it can be seen that all the Indian banks exhibit the volatility clustering effects that are specifically substantial during $2007-2009$ as also observed by Ramprasad et al. [23] and also observed in 2017-2019. The CoVaR range was maximum in the case of PNB, i.e., from 0 to $40 \%$. But the rest of the public banks contributed to systemic risk to a maximum level of $20 \%$. PNB displays the highest CoVaR values during 2017-2018 due to the 1.8 billion dollars fraud.

While comparing the private sector banks, the CoVaR values ranged from $0 \%$ to $99 \%$ in the case of HDFC banks and $0 \%$ to $40 \%$ in ICICI and AXIS banks. The HDFC and ICICI banks spread the systemic risk to others during the subprime crisis periods the most, and hence after they contributed the most, around $20 \%$. In comparison, the AXIS 


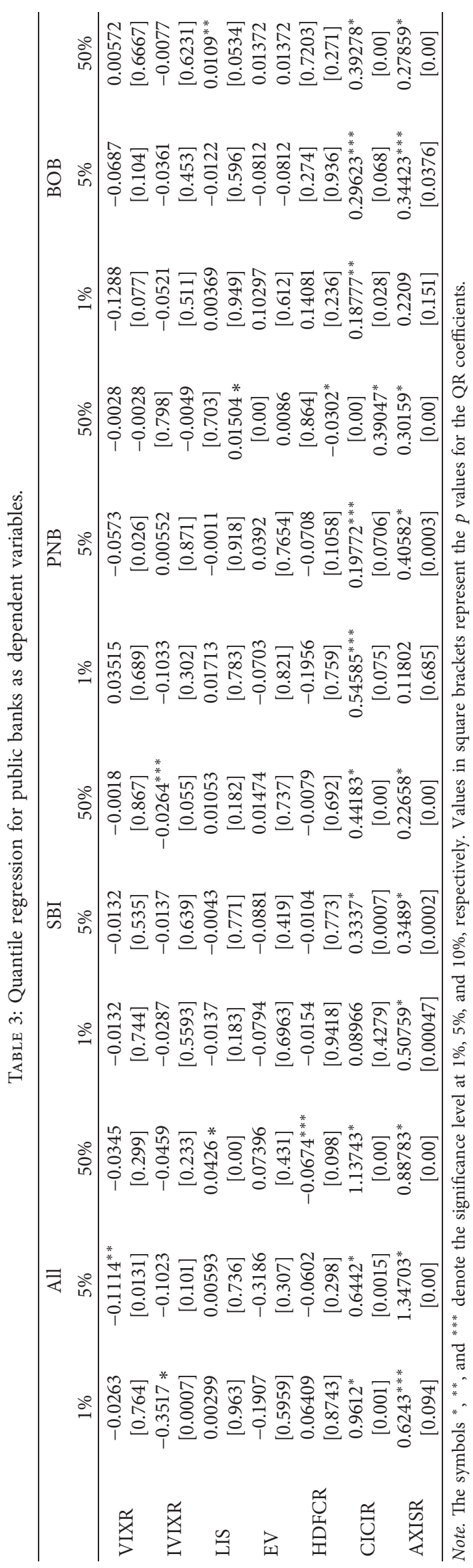




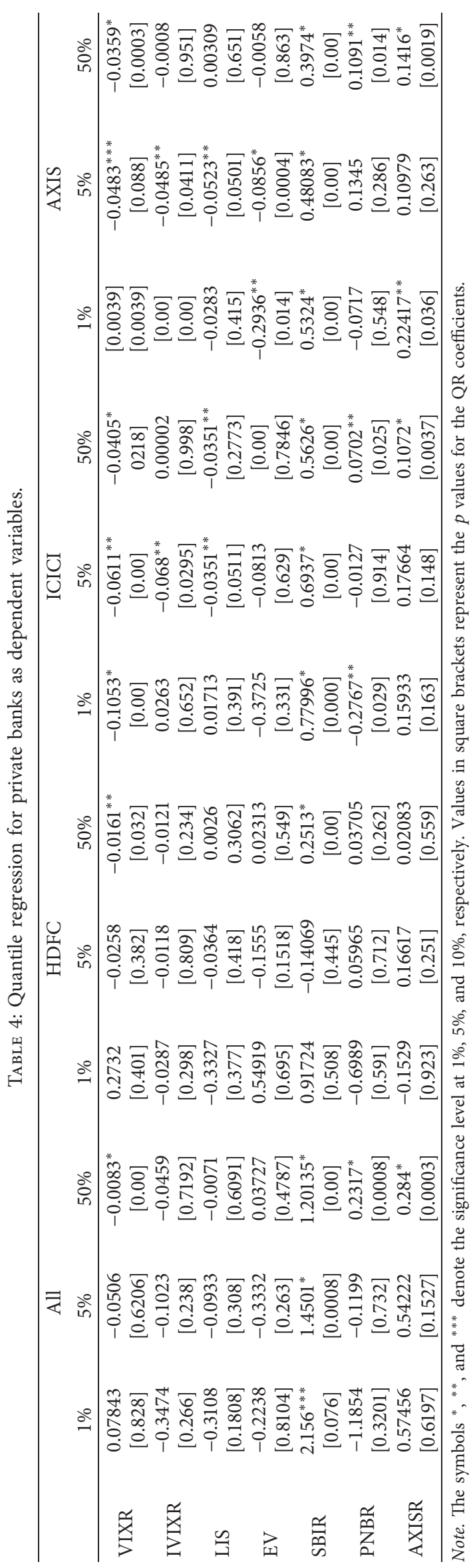


TABLE 5: Summary of time-varying VaR estimates.

\begin{tabular}{|c|c|c|c|c|c|}
\hline \multicolumn{3}{|c|}{ VaR of public banks } & \multicolumn{3}{|c|}{ VaR of private banks } \\
\hline & $5 \%$ & $50 \%$ & & $5 \%$ & $50 \%$ \\
\hline & $S B I$ & & \multicolumn{3}{|c|}{ HDFC } \\
\hline Median & -0.07145 & 0.00021 & Median & -0.04033 & 0.0047 \\
\hline Mean & -0.08017 & -0.0007 & Mean & -0.07718 & 0.00489 \\
\hline \multirow[t]{2}{*}{ Std dev } & 0.02113 & 0.02113 & Std dev & 0.01699 & 0.01699 \\
\hline & $P N B$ & & \multicolumn{3}{|c|}{ ICICI } \\
\hline Median & -0.0823 & 0.00056 & Median & -0.0597 & 0.002234 \\
\hline Mean & -0.08967 & -0.0017 & Mean & -0.0687 & 0.002627 \\
\hline \multirow[t]{2}{*}{ Std dev } & 0.02438 & 0.0244 & Std dev & 0.02904 & 0.029036 \\
\hline & $B O B$ & & \multicolumn{3}{|c|}{ AXIS } \\
\hline Median & -0.07512 & 0.00071 & Median & -0.06764 & 0.001845 \\
\hline Mean & -0.08337 & 0.00025 & Mean & -0.07525 & 0.002456 \\
\hline Std dev & 0.02345 & 0.02344 & Std dev & 0.02655 & 0.02655 \\
\hline
\end{tabular}

TABle 6: Summary of time-varying CoVaR estimates.

\begin{tabular}{|c|c|c|c|c|c|c|c|}
\hline \multicolumn{4}{|c|}{ CoVaR of public banks } & \multicolumn{4}{|c|}{ CoVaR of private banks } \\
\hline & $1 \%$ & $5 \%$ & $50 \%$ & & $1 \%$ & $5 \%$ & $50 \%$ \\
\hline SBI & & & & \multicolumn{4}{|c|}{$H D F C$} \\
\hline Median & -0.05014 & -0.05182 & -0.0021 & Median & -0.06288 & -0.06409 & 0.01997 \\
\hline Mean & -0.05516 & -0.05609 & -0.00114 & Mean & -0.07048 & -0.07595 & 0.01785 \\
\hline Std dev & 0.04379 & 0.03162 & 0.01665 & Std dev & 0.06133 & 0.088085 & 0.25186 \\
\hline$P N B$ & & & & \multicolumn{4}{|c|}{ ICICI } \\
\hline Median & -0.05395 & -0.05337 & -0.00098 & Median & -0.04621 & -0.04466 & 0.004288 \\
\hline Mean & -0.06401 & -0.06342 & -0.0037 & Mean & -0.05365 & -0.05233 & 0.001625 \\
\hline Std dev & 0.053387 & 0.05328 & 0.04391 & Std dev & 0.055012 & 0.054234 & 0.05466 \\
\hline$B O B$ & & & & \multicolumn{4}{|c|}{ AXIS } \\
\hline Median & -0.05168 & -0.05044 & 0.001654 & Median & -0.05102 & -0.04996 & 0.00639 \\
\hline Mean & -0.05591 & -0.05545 & 0.006376 & Mean & -0.05772 & -0.05642 & 0.00647 \\
\hline Std dev & 0.041145 & 0.040391 & 0.09052 & Std dev & 0.05106 & 0.05085 & 0.04956 \\
\hline
\end{tabular}

bank exhibited the highest CoVaR during the COVID-19 crisis period, which ranged up to $40 \%$. Thus, from the timevarying estimates, it can be concluded that the contribution of private banks to the systemic risk is marginally higher than the public banks. Further, the contribution of public banks stands visibly enhanced during the recent period.

Figure 2 presents the rolling $\Delta \mathrm{CoVaR}$ estimates depicting the difference in CoVaR when the bank $i$ is in a normal state defined by $50 \%$ quantile (marked in blue) and CoVaR when the bank $i$ is in a distressed state defined by $1 \%$ quantile (marked in red). $\Delta \mathrm{CoVaR}$ is the incremental Value at Risk inflicted on the financial system when it is in distress. It can be observed that the incremental contribution for SBI when it is shifting from median VaR to extreme tail VaR at $5 \%$ is high during the financial crisis. However, it remains constant throughout the whole sample period. Only during 2019, incremental contribution narrowed down. For PNB, the incremental contribution was high during GFC, then it narrowed to a constant range and witnessed a spike in the $\triangle \mathrm{CoVaR}$ during 1.8-billion-dollar fraud in 2017 and 2018, which continued until the end of the sample period. For $\mathrm{BOB}, \Delta \mathrm{CoVaR}$ values were extremely high during the financial crisis followed by a sustained $\Delta \mathrm{CoVaR}$ till 2017 . But after 2018, a sudden spike in $\Delta \mathrm{CoVaR}$ was observed due to the merger announced in September 2018, subsumed to a normal range until the end.
The $\Delta \mathrm{CoVaR}$ values were extraordinarily high and volatile for all the private sector banks during the financial crisis. For HDFC bank, $\triangle \mathrm{CoVaR}$ reached a new high during late 2016 and 2017; henceforth, it reached a normal range. For ICICI and AXIS banks, $\Delta$ CoVaR widened after 2015 to mark the growing importance of private banks.

It can be concluded that $\Delta \mathrm{CoVaR}$ was time-varying and heterogeneous across the set of public and private banks. Where SBI maintained its incremental contribution throughout the system of banks, HDFC observed a sudden rise in the incremental contribution, possibly due to the greater exposure to unsecured retail credit and company credit resulting in the mounting of the nonperforming assets, Nachiket [50].

The ICICI and AXIS banks progressively contributed after the Chinese stock market crash. Therefore, evidence for size and systemic risk contribution linkage can be inferred at this stage. HDFC bank is the highest risk contributor, followed by SBI, ICICI, and AXIS banks. But a clear ranking is not possible to allocate across the banks as the $\Delta \mathrm{CoVaR}$ tends to vary with time. The tail interconnected network graphs were analyzed to facilitate a clear comparison of the significant risk contributor and receiver.

3.6. Aggregated Analysis. Figure 3 depicts the pattern of total connectedness and average connectedness denoted by blue and dashed lines, respectively, from 2007 to 2020 at 5\% 


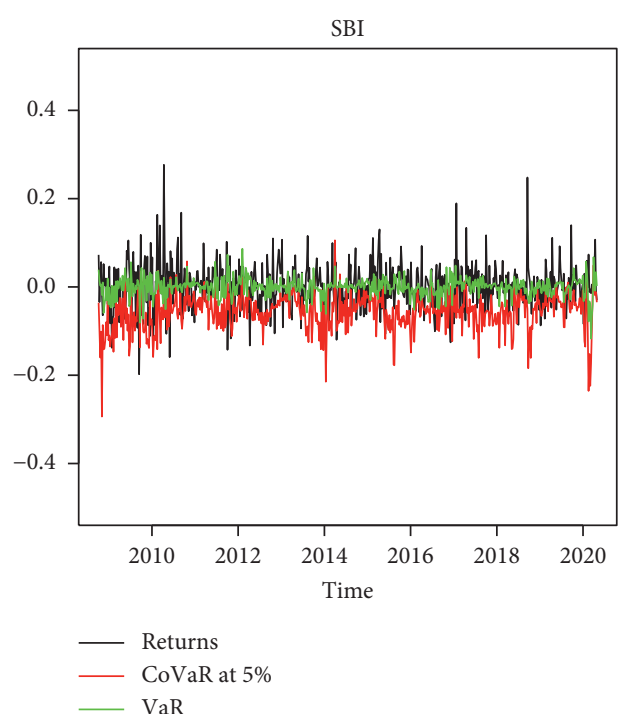

(a)

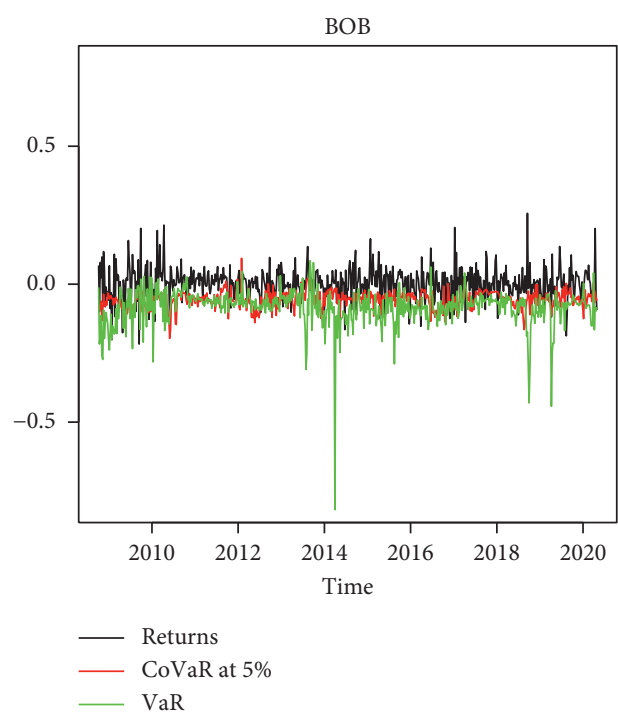

(c)

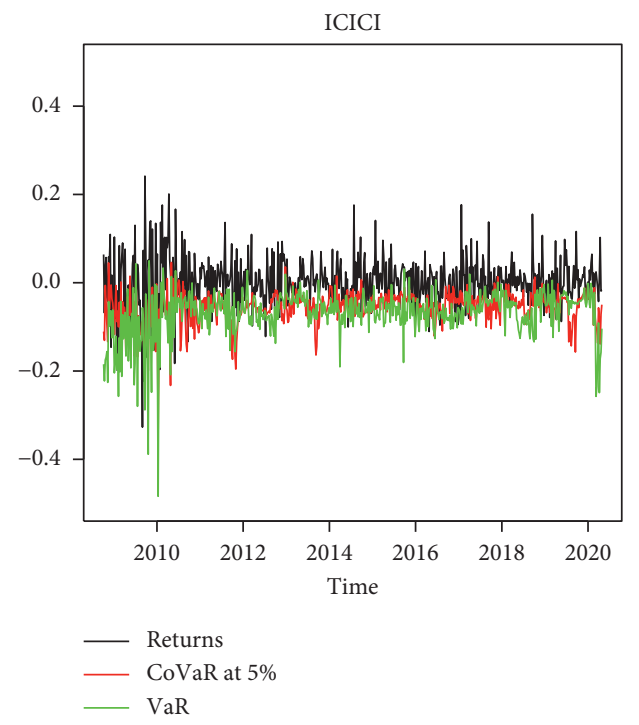

(e)

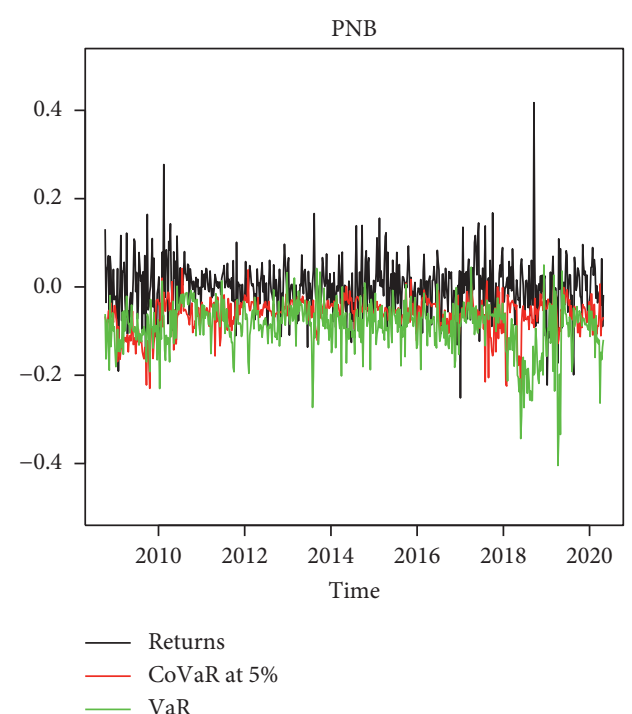

(b)

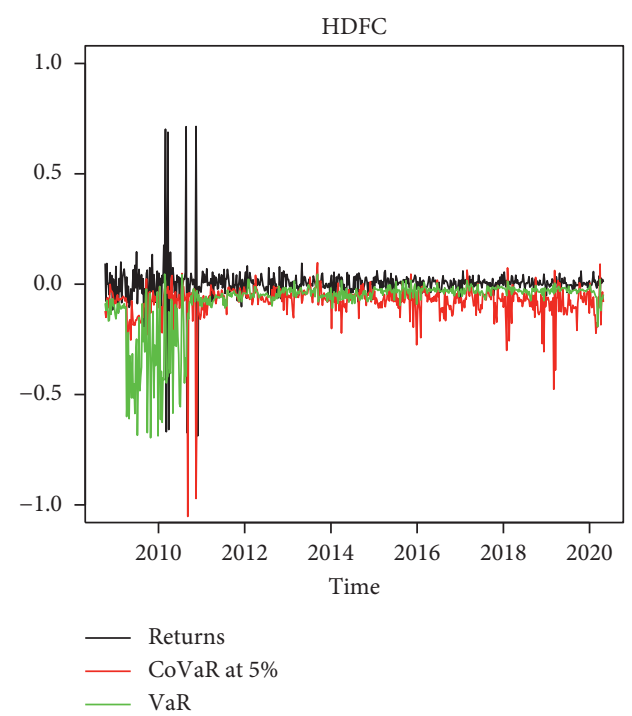

(d)

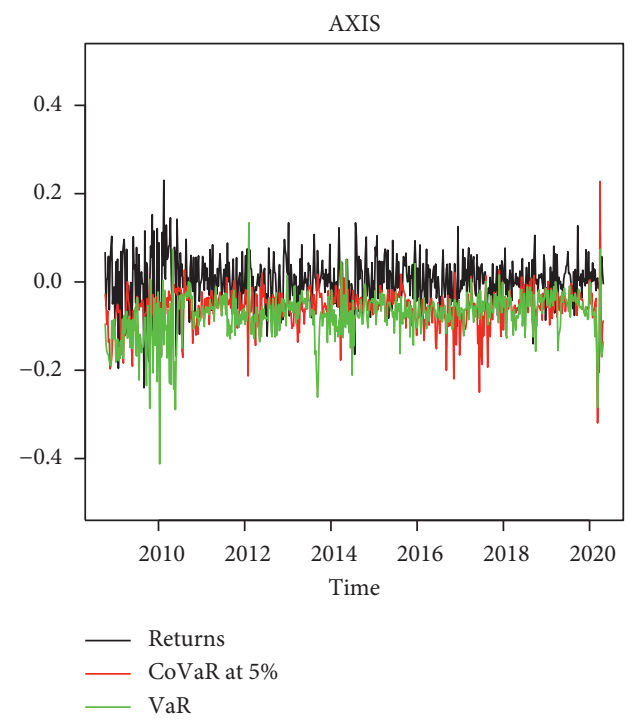

(f)

Figure 1: (a) SBI, (b) PNB, (c) BOB, (d) HDFC, (e) ICIC, and (f) AXIS. 


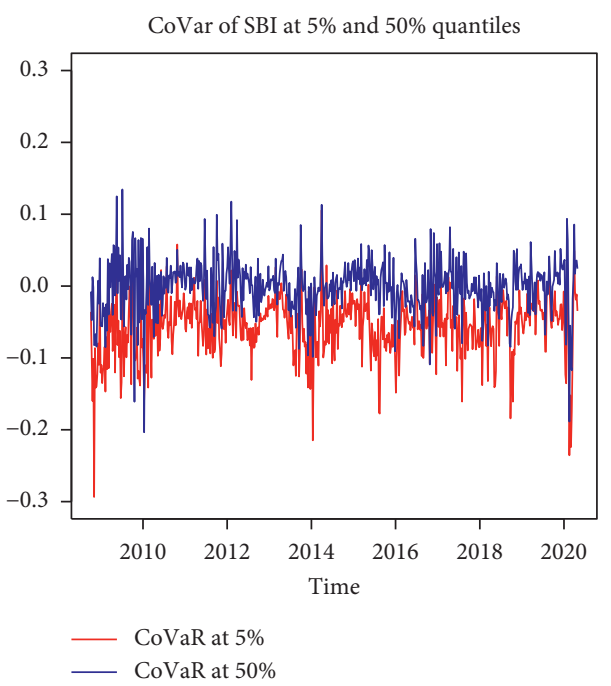

(a)

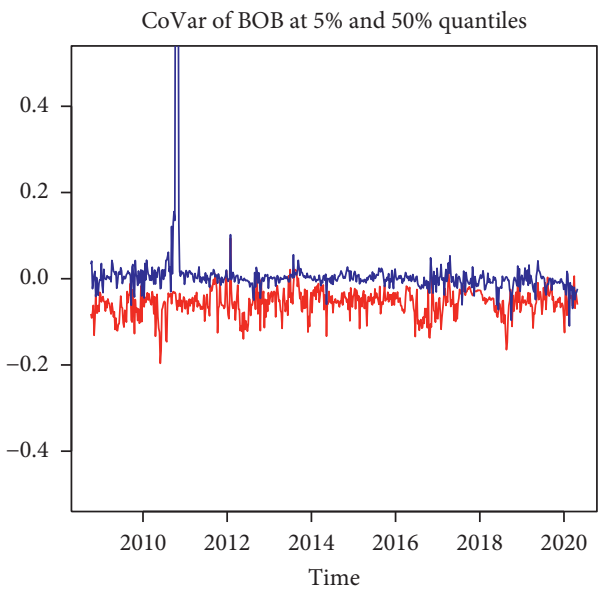

- $\mathrm{CoVaR}$ at 5\%

- CoVaR at 50\%

(c)

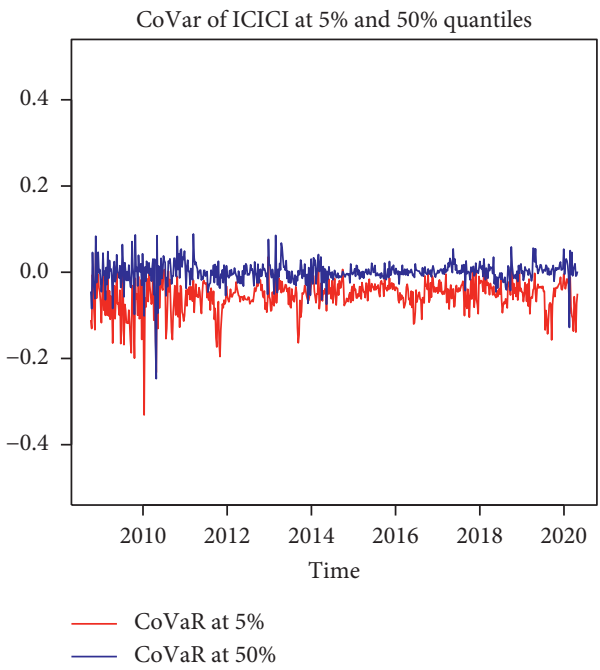

(e)

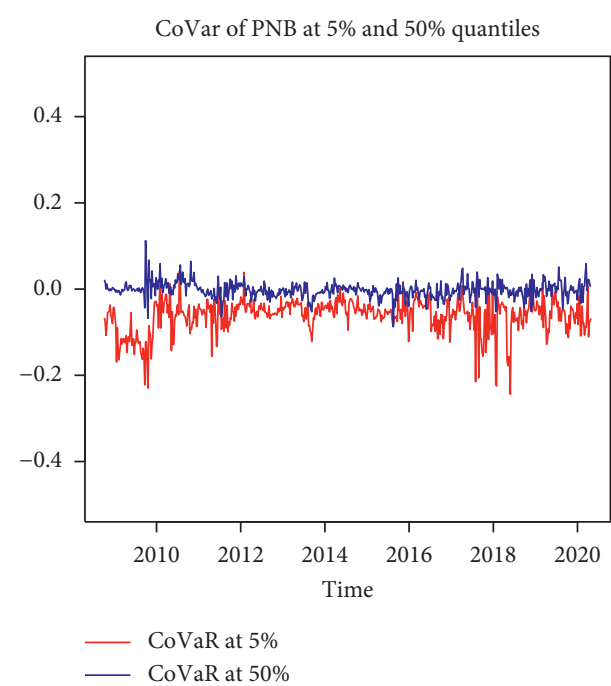

(b)

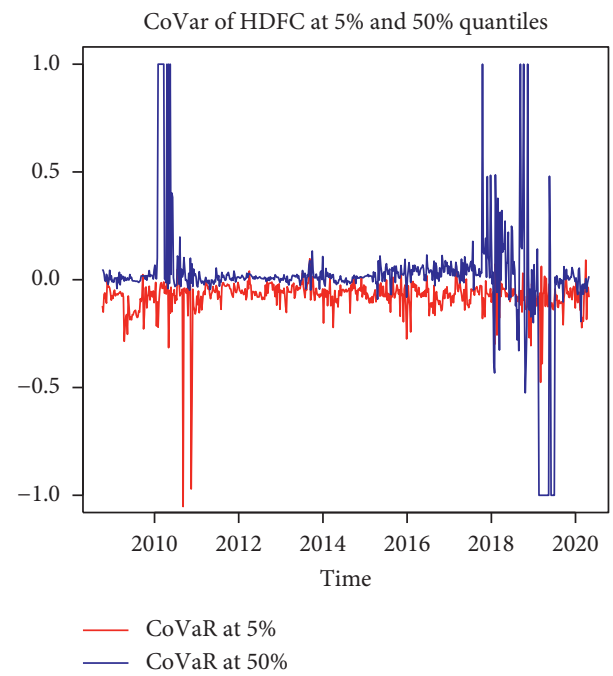

(d)

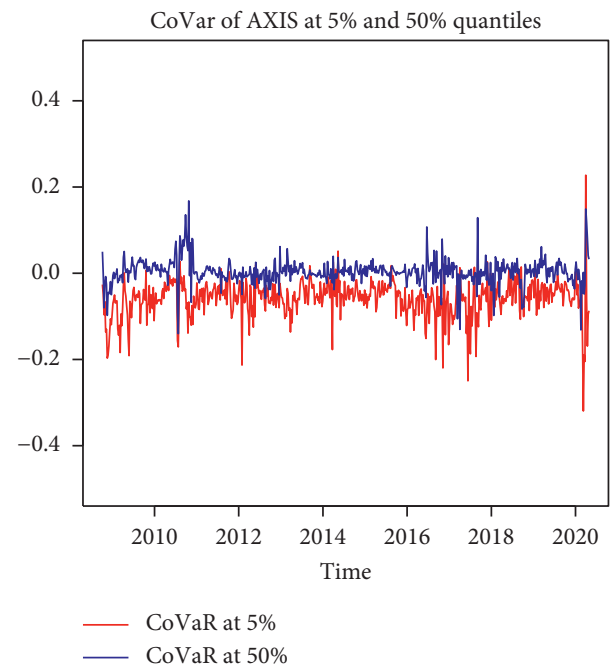

(f)

Figure 2: (a) CoVar of SBI at 5\% and 50\% quantiles. (b) CoVar of PNB at 5\% and 50\% quantiles. (c) CoVar of BOB at 5\% and 50\% quantiles. (d) CoVar of HDFC at 5\% and 50\% quantiles. (e) CoVar of ICICI at 5\% and 50\% quantiles. (f) CoVar of AXIS at 5\% and 50\% quantiles. 


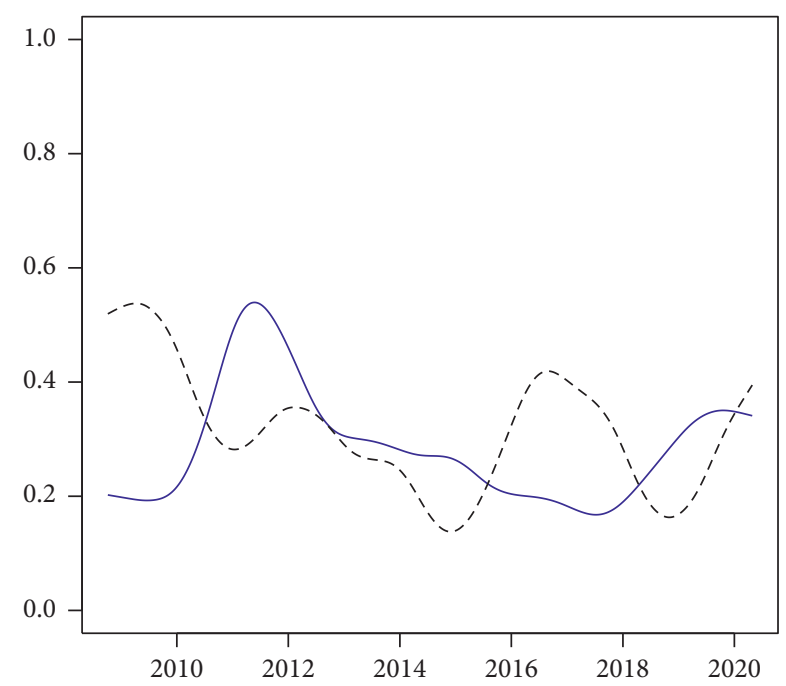

Figure 3: The pattern of total connectedness and average connectedness.

quantile. On comparing the results at $1 \%$ quantile, a similar pattern of total connectedness was revealed. To avoid any redundancy, only the $5 \%$ quantile graph was presented. It represents the total spillover arising in the banking industry as a whole.

This graph reveals that the top Indian banks were connected strongly throughout the Global Financial Crisis, which was captured by average lambda measure and continued until the end of the European Financial Crisis of 2012. It was only at the inception of 2010 that total connectedness was soaring to the highest level due to the mounting of the stressed asset in the banks' balance sheet. The strong correlations faded away from 2012 to 2015. From 2016 to 2018, the average correlation strengthened. It was due to the efforts taken by RBI to recapitalize the bank's balance sheet and the introduction of the Indian Bankruptcy Code in 2016. But the total connectedness appears to rise again after 2018 due to the severe liquidity crunch experienced by the Indian banking system due to the IL\&FS crisis as per the Economic Survey [51]. Even after the consolidation and recapitalization measures taken by the government and RBI in 2019, the total connectedness remains elevated.

Figure 4 represents the tail interconnectedness of all the Indian banks. The node represents the bank size which is denoted by market capitalization. The edges represent the tail interdependence of the Indian banks. The strength of connectedness was the highest in $\mathrm{BOB}$ and $\mathrm{SBI}, \mathrm{BOB}$ and PNB, AXIS and PNB, PNB and HDFC, and PNB and ICICI pairs. The interdependence of $\mathrm{BOB}$ and $\mathrm{PNB}$ was the strongest.

Further examination reveals that medium-sized banks like $\mathrm{PNB}$ and $\mathrm{BOB}$ show a stronger degree of connectedness. PNB reflects bilateral and unilateral connections to every bank and acts as a risk emitter except for SBI. The government banks, like BOB and PNB, exhibited strong directional linkages with other banks.

According to the ranking based on the market capitalization depicted from Table 7, the top three banks which are

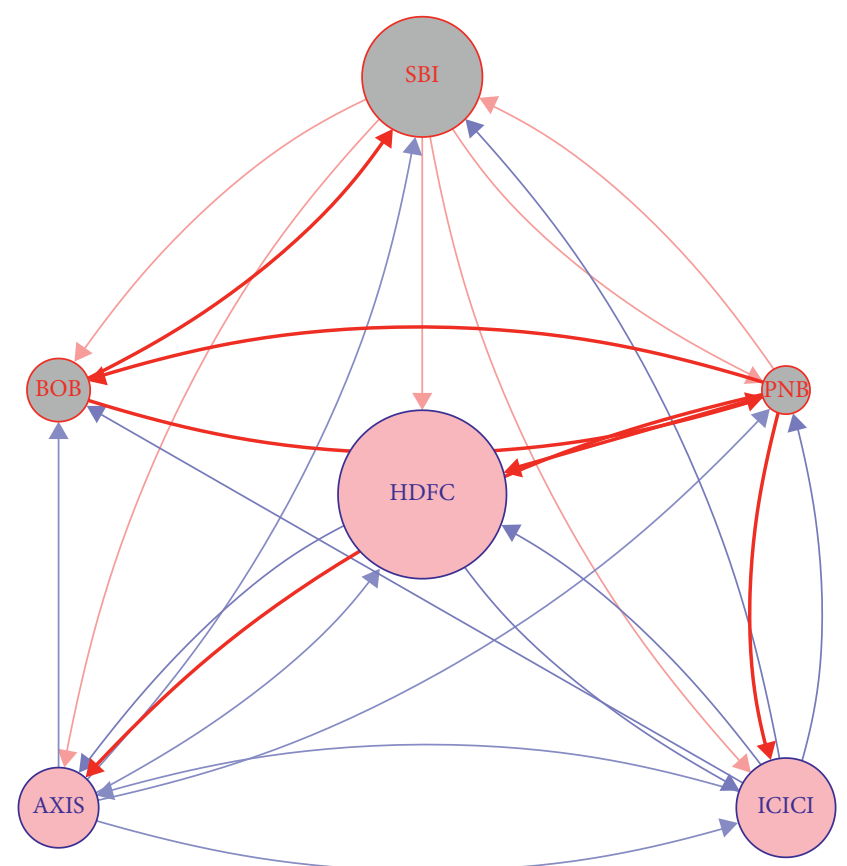

Public banks

Private banks

FIGURE 4: Interconnectedness of all the Indian banks.

TABLE 7: Rankings of Indian banks based on the market capitalization.

\begin{tabular}{|c|c|c|c|c|c|c|c|}
\hline \multicolumn{4}{|c|}{ Systemic risk receiver } & \multicolumn{4}{|c|}{ Systemic risk emitters } \\
\hline $\begin{array}{l}\text { SL. } \\
\text { no. }\end{array}$ & Banks & SRR & Ranks & $\begin{array}{l}\text { SL. } \\
\text { no. }\end{array}$ & Banks & SRR & Ranks \\
\hline 1 & SBI & $8.36 E+22$ & 5 & 1 & SBI & $5.20 E+24$ & 3 \\
\hline 2 & BOB & $5.12 E+22$ & 6 & 2 & BOB & $7.32 E+24$ & 1 \\
\hline 3 & PNB & $8.67 E+24$ & 1 & 3 & PNB & $7.75 E+22$ & 6 \\
\hline 4 & HDFC & $5.24 E+24$ & 2 & 4 & HDFC & $7.00 E+24$ & 2 \\
\hline 5 & ICICI & $4.16 E+24$ & 3 & 5 & ICICI & $2.46 E+24$ & 4 \\
\hline 6 & AXIS & $3.94 E+24$ & 4 & 6 & AXIS & $9.46 E+22$ & 5 \\
\hline
\end{tabular}

classified as systemic risk receiver are PNB, HDFC, and ICICI. In comparison, the banks which are systemic risk emitters are BOB, HDFC, and SBI. The banks with lower market capitalization seem to strengthen their influence over the central banks.

\section{Conclusion}

The results suggest that both the public and private banks are sensitive to state variables in the distress period like Indian VIX and US VIX. However, the sensitivity of private banks to liquidity risk is negative, implying a panic behavior of investors leading to the sale of stocks of private banks and less public confidence in private banks except for HDFC.

HDFC bank displayed resilience to state variables but still observed the highest Value at Risk during GFC, as found by Eichengreen and Gupta [8]. Finally, the systemic risk contribution exhibited dynamic behavior across the banks when an extreme situation arises, as seen by Jiang and Zhang 
[29]. The contribution of private banks like AXIS and ICICI banks substantially increased after 2015. On the other hand, SBI continues to maintain a standard range of marginal contribution to systemic risk, indicating its importance over the years. The TENET graphs depict that the overall connectedness was high during the GFC. The elevated level of connectedness was reverted during 2016, which got eventually subdued by efforts taken by RBI. Further, the new pattern of connectedness was vigilant after the 2018 NBFC crisis.

$\mathrm{BOB}, \mathrm{HDFC}$, and ICICI were the risk contributors to the whole system in terms of market capitalization. Thus, the large-size banks in terms of market capitalization like HDFC and SBI tend to contribute more, as was found by Ramprasad et al. [23].

The intensification of the systemic risk contribution across the private banks and banks with a lower market capitalization in India forms the peculiarity of the Indian banking system. It is a cause of concern for the regulators. With the banks' growing market capitalization and asset base, distress in these banks will potentially bring distress to the other financial institutions and the economy. Moreover, these banks can act as a conduit to transfer risk to larger and public banks like SBI through "deposit flight," which encourages them to leverage in risky projects Eichengreen and Gupta [8].

This problem aggravated by the implicit government guarantee eventually will cause "too big to fail" consequences.

However, to inflict public confidence in private bank deposits, recent measures to enhance the deposit insurance limit to Rs 0.5 million, and direct fund transfer to depositors along with a stricter vigilance over its defaults as put by Nathan [52] is a step forward. Similarly, valuable insights can be drawn from the study to develop early warning signals [53].

\section{Data Availability}

The data used to support the findings of this study are available from the corresponding author upon request.

\section{Additional Points}

Further Readings. Contagion risk in financial sector: Fitch says 30\% of banks' NBFC exposure could turn bad (The Financial Express).

\section{Conflicts of Interest}

The authors declare that they have no conflicts of interest.

\section{References}

[1] T. Adrian and M. K. Brunnermeier, "CoVaR," American Economic Review, vol. 106, no. 7, pp. 1705-1741, 2016.

[2] C. Borio, Towards a Macroprudential Framework for Financial Supervision and Regulation, Bank of International Settlements, Basel, Switzerland, 2003.
[3] R. N. Mishra, G. Mohan, and S. Sanjay, Systemic Liquidity Index for India, Reserve Bank of India, New Delhi, India, 2012.

[4] J. Kleinow and T. Nell, "Determinants of systemically important banks: the case of Europe," Journal of Financial Economic Policy, vol. 7, no. 4, pp. 446-476, 2015.

[5] V. Acharya and S. Steffen, Analyzing Systemic Risk of the European Banking Sector Handbook on Systemic Risk, Cambridge University Press, Cambridge, UK, 2012.

[6] K. C. Chakrabarty, "Framework for macroprudential policy in India: experiences and perspectives," Financial Stability Review, vol. 18, pp. 131-144, 2014.

[7] (2020).Indian financial services industry report. https://www. ibef.org/industry/financial-services-india.aspx.

[8] B. Eichengreen and P. Gupta, "The financial crisis and Indian banks: survival of the fittest?" Journal of International Money and Finance, vol. 39, pp. 138-152, 2013.

[9] (2020). Indian banking industry report. https://www.ibef.org/ industry/banking-india.aspx.

[10] (2017). The festering twin balance sheet problem. https:// www.indiabudget.gov.in/budget2017-2018/es2016-17/ echap04.pdf.

[11] (2019). December 2019 financial stability report. https://www. rbi.org.in/Scripts/BS_PressReleaseDisplay.aspx?prid=48982.

[12] A. Subramanian and J. Felman, "India's great slowdown: what happened? What's the way out?" Center for International Development at Harvard University, Cambridge, MA, USA, 2019.

[13] M. Brunnermeier and L. H. Pedersen, "Market liquidity and funding liquidity," Review of Financial Studies, vol. 22, no. 6, pp. 201-202, 2009.

[14] G. B. Gorton and A. Metrick, Securitized Banking and the Run on Repo, NBER, Cambridge, MA, USA, 2009.

[15] D. Greenlaw, A. K. Kashyap, K. L. Schoenholtz, and H. S. Shin, "Stressed out: macroprudential principles for stress testing," Chicago Booth Research Paper No. 12-08, University of Chicago, Chicago, IL, USA, 2012.

[16] O. Burrows, D. Learmonth, and J. McKeown, RAMSI: A TopDown Stress Testing Model, Bank of England, London, UK, 2012.

[17] F. Erdem, Pinar; etkin özen and ibrahim ünalmiş are Macroprudential Policies Effective Tools To Reduce Credit Growth In Emerging Markets?, Central Bank :Republic of Turkey, Ankara, Turkey, 2017.

[18] C. T. Brownlees and R. F. Engle, Volatility, Correlation and Tails for Systemic Risk Measurement, 2012, http://citeseerx.ist. psu.edu/viewdoc/summary?doi=10.1.1.405.4638.

[19] V. V. Acharya, L. H. Pedersen, T. Philippon, and M. Richardson, "Measuring systemic risk," Review of Financial Studies, vol. 30, no. 1, pp. 2-47, 2017.

[20] M. Demirer, F. X. Diebold, L. Liu, and K. Yilmaz, "Estimating global bank network connectedness," Journal of Applied Econometrics, vol. 33, no. 1, pp. 1-15, 2018.

[21] G.-J. Wang, C. Xie, K. He, and H. E. Stanley, "Extreme risk spillover network: application to financial institutions," Quantitative Finance, vol. 17, no. 9, pp. 1417-1433, 2017.

[22] W. K. Härdle, W. Wang, and L. Yu, "TENET: tail-event driven NETwork risk," Journal of Econometrics, vol. 192, no. 2, pp. 499-513, 2016.

[23] R. Verma, W. Ahmad, G. S. Uddin, and S. Bekiros, "Analysing the systemic risk of Indian banks," Economics Letters, vol. 176, pp. 103-108, 2019.

[24] A. Das and S. Ghosh, "Financial deregulation and efficiency: an empirical analysis of Indian banks during the post reform 
period," Review of Financial Economics, vol. 15, no. 3, pp. 193-221, 2006.

[25] R. Sengupta and H. Vardhan, "Non-performing assets in Indian banks: this time it is different," Economic \& Political Weekly, vol. 52, no. 12, pp. 85-95, 2017.

[26] R. Gulati, A. Goswami, and S. Kumar, "What drives credit risk in the Indian banking industry? an empirical investigation," Economic Systems, vol. 43, no. 1, pp. 42-62, 2019.

[27] M. Billio, M. Getmansky, A. W. Lo, and L. Pelizzon, "Econometric measures of connectedness and systemic risk in the finance and insurance sectors," Journal of Financial Economics, vol. 104, no. 3, pp. 535-559, 2012.

[28] S. Gosh, "Bank aversion to nbfcs fuelled india's liquidity crisis. mint," 2018, https://www.livemint.com/Money/VSodCnfdh5 p47h6Nf0BF6K/Bank-aversion-to-NBFCs-fuelled-Indias-liq uidity-crisis.html.

[29] H. Jiang and J. Zhang, "Discovering systemic risks of China's listed banks by CoVaR approach in the digital economy era," Mathematics, vol. 8, no. 2, p. 180, 2020.

[30] T. H. Le, "Systemic risk in ASEAN-6: a new empirical investigation," International Journal of Emerging Market, 2021.

[31] E. Elyasiani and J. Jia, "Relative performance and systemic risk contributions of small and large banks during the financial crisis," The Quarterly Review of Economics and Finance, vol. 74, pp. 220-241, 2019.

[32] E. N. Karimalis and N. K. Nomikos, "Measuring systemic risk in the European banking sector: a copula CoVaR approach," The European Journal of Finance, vol. 24, no. 11, pp. 944-975, 2018.

[33] J. Yun and H. Moon, "Measuring systemic risk in the Korean banking sector via dynamic conditional correlation models," Pacific-Basin Finance Journal, vol. 27, pp. 94-114, 2014.

[34] R. Roengpitya and P. Rungcharoenkitkul, Measuring Systemic Risk and Financial Linkages in the Thai Banking System, Monetary Policy Group: Bank of Thailand, Bangkok, Thailand, 2010.

[35] S. Q. Hashem and I. Abdeljawad, "Chapter 2 islamic banks' resilience to systemic risks: myth or reality-evidence from Bangladesh," Management of Islamic Finance: Principle, Practice, and Performance, vol. 19, pp. 37-68, 2018.

[36] Q. Huang, J. De Haan, and B. Scholtens, "Analysing systemic risk in the Chinese banking system," Pacific Economic Review, vol. 24, no. 2, pp. 348-372, 2019.

[37] W.-Q. Huang, X.-T. Zhuang, S. Yao, and S. Uryasev, “A financial network perspective of financial institutions' systemic risk contributions," Physica A: Statistical Mechanics and Its Applications, vol. 456, pp. 183-196, 2016.

[38] G. P. Clemente, R. Grassi, and C. Pederzoli, "Networks and market-based measures of systemic risk: the European banking system in the aftermath of the financial crisis," Journal of Economic Interaction and Coordination, vol. 15, no. 1, pp. 159-181, 2020.

[39] M. Chabot and J. L. Bertrand, "Complexity, interconnectedness and stability: new perspectives applied to the European banking system," Journal of Business Research, vol. 129, pp. 784-800, 2019.

[40] O. Bernal, J.-Y. Gnabo, and G. Guilmin, "Assessing the contribution of banks, insurance and other financial services to systemic risk," Journal of Banking \& Finance, vol. 47, pp. 270-287, 2014.

[41] G. Girardi and A. Tolga Ergün, "Systemic risk measurement: multivariate GARCH estimation of CoVaR," Journal of Banking \& Finance, vol. 37, no. 8, pp. 3169-3180, 2013.
[42] C. Castro and S. Ferrari, "Measuring and testing for the systemically important financial institutions," SSRN Electronic Journal, vol. 25, pp. 1-14, 2012.

[43] F. X. Diebold and K. Y1lmaz, "On the network topology of variance decompositions: measuring the connectedness of financial firms," Journal of Econometrics, vol. 182, no. 1, pp. 119-134, 2014.

[44] G.-J. Wang, S. Yi, C. Xie, and H. E. Stanley, "Multilayer information spillover networks: measuring interconnectedness of financial institutions," Quantitative Finance, vol. 21, no. 7, pp. 1163-1185, 2021.

[45] G.-J. Wang, Y.-Y. Chen, H.-B. Si, C. Xie, and J. Chevallier, "Multilayer information spillover networks analysis of China's financial institutions based on variance decompositions," International Review of Economics \& Finance, vol. 73, pp. 325-347, 2021.

[46] S. Giglio, B. Kelly, S. Pruitt, and X. Qiao, "Systemic risk and the macroeconomy: an empirical evaluation," Journal of Financial Economics, vol. 119, pp. 457-471, 2012.

[47] M. Bianconi, X. Hua, and C. M. Tan, "Determinants of systemic risk and information dissemination," International Review of Economics \& Finance, vol. 38, pp. 352-368, 2015.

[48] (2011). Systemic Risk Assessment. https://www.rbi.org.in/ scripts/PublicationReportDetails.aspx?ID=656.

[49] H. S. Shin, Macroprudential Policies beyond Basel III, Policy Memo, Princeton University, Prinston, NJ, USA, 2010.

[50] K. Nachiket, "Will high exposure to unsecured consumer credit help or hurt hdfc bank? analysts differ. the week," 2020, https:/www.theweek.in/news/biz-tech/2020/03/20/will-highexposure-to-unsecured-consumer-credit-help-or-hurt-hdfcbank-analysts-differ.html.

[51] (2019-20). Monetary Management and Financial Intermediation. https://www.indiabudget.gov.in/budget2019-20/econo micsurvey/doc/vol2chapter/echap03_vol2.pdf.

[52] N. Nathan, "Just raising deposit cover to rs 5 lakh won't help," 2020, https://economictimes.indiatimes.com/wealth/persona l-finance-news/just-raising-deposit-cover-to-rs-5-lakh-wonthelp/articleshow/74073305.cms?from $=\mathrm{mdr}$.

[53] 10 Largest Banks in India by Market cap, 2020, https://www. businesstoday.in/photos/bt-newsflicks/10-largest-banks-inindia-by-total-assets-state-bank-of-india-punjab-national/ 1479.html\#photo6. 